\title{
As bases filosóficas e históricas do cuidado e a convocação de parceiros sexuais em HIV/aids como forma de cuidar
}

\author{
The philosophical and historical bases of the care \\ and the call of sexual partners in HIV/AIDS as a form to look after
}

Priscilla M esquita Luz ${ }^{1}$

KarlaCorrea Lima M iranda ${ }^{1}$

Abstract This is an article in which we discuss the concept of the care according to the perspective of the philosophy, linking with the practice of the nurses, who appropriates themsel ves of this concept to substantiate their professional practice. We defend that a way to look after with ethics can be carried out when the professional call upon the partners of the HIV/AIDS infected patients. We believe that this moment is very delicate and deserves to be argued and to be institutionalized by the professional team that carries out the specialized attendance in HIV/AIDS. Key words Philosophy, Care, Sexual partners, HIV/AIDS
Resumo Trata-se de um artigo no qual discutimos o conceito do cuidado na perspectiva da filosofia, articulando-o com a prática do enfermeiro, que se apropria desse conceito para fundamentar sua prática profissional. Defendemos que uma maneira de cuidar com ética pode ser realizada na convocação dos parceiros de portadores do HIV / aids. A creditamos que esse momento é de grande delicadeza e merece ser discutido e institucionalizado pela equi peinterdisci plinar que realiza atendimento especializado em HIV/aids.

Palavras-chave Filosofia, Cuidado, Parceiros sexuais, HIV/aids 


\section{As bases filosóficas do cuidado}

A palavra cuidado, segundo os dicionários clássicos de filologia, deriva do latim cura (coera) e era usada em contextos de relações de amor e amizade. Expressava a atitude de cuidado, de desvelo, de preocupação e de inquietação pela pessoa ou objeto estimados ${ }^{1}$.

Outros filólogos consideram que a origem da palavra encontra-se em cogitare-cogitatus e suas derivações coeydar, coidar, cuidar. 0 sentido é similar ao de cura: ter atenção, interesse, atitude de desvelo e preocupação. Logo, o cuidado se apresenta quando algo ou alguém tem importância para nós. A dedicação ea disponibilidade de participação, o sentimento dezelo ea responsabilidade realizam o cuidado ${ }^{1}$.

Nesse sentido, cuidado é um modo-de-serno-mundo, que fundamenta as relações que se estabelecem com todas as coisas. No jogo de relações, na coexistência e convivência, o ser humano edifica seu próprio ser, sua autoconsciência e sua própria identidade².

Segundo Boff², existem duas maneiras básicas deexistir: pelo trabal ho epelo cuidado. Logo, a construção da realidade passa a ter seu processo emergente a partir dessas dimensões. Para a humanidade, o trabalho se transforma em um modo-de-ser conscienteeassumea marca deum projeto, com suas manobras de modelagem de si mesmo e da natureza. Entretanto, a busca pela superação dos desafios impostos pela natureza levou o ser humano a aprofundar sua capacidade deinterpretação e intervenção. Essa racionalidade leva o ser humano a uma objetividade cada vez mais imediata por uma tecnologia que acaba por robotizar e fragmentar a ação humana, distanciando-o da natureza.

Para Boff², cuidar das coisas implica em: ter intimidade, senti-las dentro, acolhêlas, respeitálas, dar-Ihes sossego e repouso. Cuidar é entrar em sintonia com, auscutar-Ihes o ritmo e afinar-se com ele. A razão analítico-instrumental abre caminho para a razão cordial, o espírito da delicadeza, o sentimento profundo. A centralidade não é mais ocupada pelo logos razão, mas pelo pathos sentimento.

Do ponto de vista existencial de Heidegger, 0 cuidado acontece antes de qualquer comportamento humano, o que significa dizer que é encontrado em toda atitude e situação de fato. 0 cuidado é o modo-de-ser essencial da humanidade. Está presente em tudo, portanto é o fenômeno ontológico-existencial básico, quer dizer, fundamental para a interpretação do sujeito ${ }^{3}$.
Para explicar o cuidado como essência da existência humana, Heidegger utilizou uma fábula de origem grega e base latina, escrita por H igino. $\mathrm{Na}$ fábula, Cuidado ou Cura passeia próximo a um rio, quando vêum pedaço de barro, quepara outros passaria despercebido. Cuidado dá forma ao que antes era barro, lama, terra, e admira o que fez. M as falta vida a sua obra. Júpiter, deus criador, aparece e Cuidado pede-lhe que incute espírito na sua obra. Ele então insufla em suas narinas o hálito da vida, e a obra feita de barro torna-se viva. M as falta dar um nome à nova criatura. Cria-se, então, um impasse. Cuidado quer dar o nome, Júpiter quer que a criatura leve seu nome e a deusa Terra deseja o mesmo, pois fora a partir dela que originalmente surgira a nova identidade. É chamado então Saturno, o deus do tempo da abundância, para resolver as divergências. Saturno julga e decide ${ }^{3}$ : A Júpiter foi prometido o espírito após a morte da criatura, já que ele tinha Ihe dado a vida; Terra, que forneceu o material do corpo, o receberá quando da sua morte; ea Cuidado, por ter sido elequem primeiro o moldou, caberá a responsabilidade dos cuidados com a criatura durante toda sua existência no mundo. 0 nome daquele ser foi decisão de Saturno, a quem chamou de Homem, porque veio do húmus, isto é, da terra fértil, ea ela voltará.

Essa fábula é a tentativa humana de revelar a realidade imaterial ontológica, desvelando a gê nese e a finitude humanas ${ }^{3}$.

Heidegger percebeu que, na imaginação de H igino, Cuidado ou Cura representava a primeira manifestação de uma característica fundamental do existir humano. 0 ser-no-mundo é muito mais do que simplesmente o estar-no-mundo. Esteé ôntico, aqueleéontológico. 0 ôntico ocupa, o ontológico preocupa-se, cuida e é percebido como algo intuído, que se constitui, de fato, no referencial de sentido para todas as ações humanas: a preocupação. E foi dessa preocupação que surgiu o homem ${ }^{3}$.

Enquanto Boff ${ }^{2}$ compreen de o cuidado como atitudefundamental deum modo-de-ser no qual a pessoa sai de si e centra-se no outro com carinho, Heidegger aponta que a origem humana está no cuidado e que esse cuidado possui uma anterioridade que imprime, mantém e domina 0 ser-no-mundo. 0 cuidado é a primeira marca humana.

Logo, o cuidado pensado aqui é entendido como ocupação e preocupação para fora de si. Essa ocupação tem o sentido primeiro de preservação de um outro, que se caracteriza pela ação: ação de cuidar. Nessa perspectiva, cuidar étarefa 
de todos, como cuidar do planeta, do país, da cidade, do outro, do familiar ou não familiar, da criança, do idoso, do que sofre, do que chora, do que pede e do que não pode pedir.

Compreender a realidade do outro, saindo desua própria referência estrutural, éo principal aspecto da dimensão ética do cuidado referido por N oddings 4 , no qual a realidade do outro nos chega de forma empática, onde a tolerância torna-se fundamental. 0 cuidado, aqui, representa um acordo, pois existe envolvimento entre as pessoas e promove o bem estar do outro, logo, é uma atitude relacional ${ }^{4}$.

Foucault 5 , ao escavar, com seu método arqueológico, a cultura grego-romana nos séculos II e III, revela uma tecnologia do cuidado de si como uma técnica ética e estética da existência. As técnicas de si revelam que quem se governa pode governar os outros, havendo assim a necessidade de cuidar de si mesmo, dos outros e da cidade. Mas, para isso, seria necessário conhecer-se, conhecer o corpo e seus limites, enfocando a questão primordial da moderação.

Foucault ${ }^{5}$ também reporta que um dos estatutos do sujeito era o sujeito do cuidado desi, que se tratava de uma prática da liberdade que implica a criação einvenção desi mesmo como sujeito. Logo, a partir do conhecimento de si, as pessoas poderiam autoprescrever dietas, exercícios, sexo, banhos, sem a necessidade de recorrer a especialistas, já quea pessoa mais indicada para esse cuidado éo próprio sujeito. 0 cuidado desi implica a relação de si consigo, um trabal ho incansável de construção de si mesmo. Para o grego a questão era: você é senhor ou escravo dos seus desejos?

Dessa forma, não existia a figura do especialista, que ditava para o outro a melhor forma de se cuidar e viver melhor. M as, com a modernidade, a inversão desse pensamento se tornará uma construção e invenção proposta pela ciência.

\section{História do cuidado no contexto da enfermagem}

A enfermagem no Brasil, como em outros países, iniciou seu percurso desvalorizando o cuidado e atendendo apenas uma ideologia decura. Asações curativas ocupavam a maior parte das atividades, utilizando tecnologias mais sofisticadas ${ }^{6}$.

N esse momento, houve um distanciamento das enfermeiras em relação aos pacientes, pois estas, devido à formação universitária, passaram a valorizar a liderança, o planejamento, o controle e a gerência, no sentido de se tornarem efi- cientes, além de controlar gastos. 0 cuidado direto passou a ser exercido pelas demais categorias de enfermagem, ratificando que o cuidado era algo de menor valor ${ }^{6}$.

Em relação ao ensino, os livros defundamentos de enfermagem eram as bíblias dos alunos. A habilidade manual, a capacidade de memorização, a postura e a mecânica corporal na realização de técnicas eram aspectos imprescindíveis, além do capricho, da organização e da perfeição. 0 objeto da enfermagem não estava centrado no cuidado ao paciente, mas na maneira da tarefa ser executada 6 .

A década de cinquenta é caracterizada pela introdução dos princípios científicos, guias norteadores de todas as ações de enfermagem, prevalecendo os aspectos biológicos, os princípios de anatomia, fisiologia, microbiologia, física e química. Agora, o cuidado de enfermagem tinha respaldo científico, uma aproximação com o saber das profissões hegemônicas. Nas escolas de enfermagem, o ensino continuava priorizando 0 conhecimento médico, acrescido de uma ênfase nas teorias administrativas de Taylor ${ }^{7}$, cujos princípios eram orientados para as ações de planejamento, organização e supervisão do cuidado administrado pelas demais categorias ${ }^{6}$.

Em meados das décadas de sessenta e setenta, as teorias de enfermagem passam a ter um papel fundamental no desenvolvimento da profissão. Várias tentativas são realizadas no sentido de humanizar o cuidado, buscando o status de ciência esua identidade ${ }^{6}$.

$\mathrm{Na}$ década de setenta, no Brasil, as teorias passam a se tornar fonte de interesse. A maioria delas desenvolvida por enfermeiras americanas, com ênfase em aspectos biomédicos, como adaptação, homeostase, necessidades humanas básicas, buscando apoio em outras áreas do conhecimento social epsicológico ${ }^{6}$.

A metodologia do processo de enfermagem, introduzida no Brasil em meados da década de setenta, sofistica-se e passa a ser implantada em al gumas instituições hospitalares, apesar de algumas resistências iniciais quanto à sua efetivação ${ }^{6}$.

Muitas teorias, que são norteadoras da prática do enfermeiro, têm sido atualizadas e várias propõem o cuidar como foco central. N elas são teorizados conceitos de homem, saúde, enfermagem, cuidado, cada qual dentro do seu fundamento epistemológico, viés teórico e correntefilosófica eleita pelo seu pensador: fenomenologia, existencialismo, marxismo, humanismo.

Vale ressaltar também que a enfermagem, além de elaborar, está sempre discutindo e avali- 
ando o processo de enfermagem. Uma das etapas desse processo é o diagnóstico de enfermagem como um instrumento de grande importância na estruturação do conhecimento, para definir o papel e o domínio próprios do enfermeiro, logo, o desenvolvimento de uma taxonomia serve para descrever e desenvolver um fundamento científico confiável ${ }^{8}$.

Portanto, podemos perceber que os profissionais de enfermagem, durante a construção da sua história eidentidade, apropriaram-sedo cuidado para se afirmar eexistir cientificamente. Fazse necessário que esses profissionais retomem e reflitam sobre o conceito filosófico do cuidado e a história de sua profissão, capturando ou sendo capturados por esse conceito.

A perspectiva do cuidado em ambulatório especializado em HIV/aids

Em meados de 1981, cientistas descobriram uma doença que gerava um quadro de imunodeficiência grave nos pacientes, chegando ao ponto de deixá-los vulneráveis a doenças oportunistas e levando-os à morte. Denominaram-na de síndromeda imunodeficiência adquirida (aids), causada pelo vírus da imunodeficiência humana (HIV). Essa pandemia resultou em medo, perda e sofrimento para as pessoas, tornando-se um desafio para a comunidade científica mundial ${ }^{9}$. No Brasil, os primeiros casos de aids surgiram em 1982, e sua disseminação iniciou-se a partir da região sudeste do país e atualmente alcança escala nacional ${ }^{10}$.

Frente à complexidade e diversidade de problemas que surgiram pela epidemia da aids, foram colocados, mundialmente, como uma das importantes estratégias de controle da transmissão do vírus HIV os testes sorológicos, que eram feitos em centros, que receberam a denominação deCentros de Testagem eAconsel hamento (CTA). Esses centros caracterizavam-se pela oferta do testesorológico anti-HIV acompanhado deaconselhamento pré e pós-exame, assegurando gratuidade, voluntariedadee confidencialidade ${ }^{11}$. No ano de 2000, mais de 150 CTA estavam funcionando no Brasil ${ }^{12}$.

A revelação do resultado do exameao pacienteéfeita na presença deum profissional desaúde, capacitado para tal, sendo ideal que, após a abertura do exame, o profissional por meio de uma escuta presentificada permita que o paciente expresse seus sentimentos, dúvidas e angústias.
Os sentimentos dos pacientes durante a descoberta da soropositividade pelo HIV são de dor e sofrimento, tornando esse atendimento bastante difícil tanto para eles quanto para o profissional, já que o diagnóstico de soropositividade está interligado aos sentimentos de morte, perda, abandono, preconceito, rejeição pelas outras pessoas, rompimento das relações e medo do desconhecido ${ }^{13}$.

De acordo com Luzia Aparecida Oliveira et al. ${ }^{14}$, presencia-se cotidianamente situações relacionadas à busca do controle da doença, questões relativas à adesão, ao tratamento e dificuldade de revelação do diagnóstico, quemuitas vezes vão de encontro aos projetos pessoais dos usuários.

Desse modo, o profissional pode se envolver diretamente com a situação, o que o leva a ficar paral isado com os sentimentos do pacientee desenvolver mecanismos de proteção, passando a considerar o portador de HIV/aids como um usuário social, econômico e culturalmente menos favorecido e que deve ser amparado; consequentemente, os próprios profissionais, que de certa maneira se comovem com a situação, assumem esse amparo. Isso facilita a criação de um vínculo entre eles, mas abre espaço, de maneira informal, para a dependência de juízos e vontades pessoais, sobretudo por parte dos profissionais ${ }^{14}$. Essa criação de juízo de valores a respeito do usuário é prejudicial para a relação profissional-paciente, e énesse momento de interação de todos esses sentimentos que o profissional encontra dificuldades, o que pode impedir que ele faça uma abordagem problematizadora na qual o outro também faça parte das discussões.

Portanto, é importante haver uma abordagem multidisciplinar e interdisciplinar entre os profissionais, para que no momento em quesurjam dificuldades em conduzir determinadas situações, ele sesinta à vontade para encaminhar 0 paciente a outro profissional, permitindo assim queo paciente falesobre seus sentimentos, sobre suas dúvidas, e obtenha orientações e informações sobre 0 assunto, pois é principalmente no aconselhamento que o profissional consegue desempenhar essas atividades.

0 cuidado ao pacientesoropositivo exigeque o profissional o veja como um ser humano, com demandas específicas, que se encontra fragilizado, portanto, merecendo respeito e atenção, 0 que muitas vezes é negado em seu ambiente familiar e de trabalho. É fundamental que os profissionais trabalhem 0 autocuidado desses pacientes com o objetivo de incentivar sua autonomia e autoestima. 
0 cuidado também está relacionado com a saúde deterceiros queserelacionam sexualmente com pacientes soropositivos. Uma forma de estar eticamente comprometido com o cuidado é atuando e promovendo a convocação dos parceiros sexuais, para que assim eles possam procurar assistência institucional para a investigação de sua condição sorológica, quebrando uma possível cadeia de transmissão do HIV. Esses parceiros poderão, assim, ser beneficiados com relação ao acesso ao serviço de saúde e suas condutas de promoção da saúde, tendo a possibilidade deum atendimento e acompanhamento especializados, favorecendo uma sobrevida do parceiro sexual.

Dessa forma, a convocação do parceiro se xual do portador do HIV/aids pelo profissional de saúde deve ser um momento de destreza e delicadeza, pois ele se torna bastante doloroso para ambas as partes. É um momento de cuidado para com o cliente e seu parceiro sexual.

Dessa forma, de acordo com estudo feito por Teixeira ${ }^{15}$, o momento ideal para se abordar essa temática seria na consulta para entrega de preservativos, pois além da condição sorológica já ter sido compreendida pelo paciente, o profissional, utilizando a educação em saúde, após abordar os aspectos relacionados ao uso ou não do preservativo, passa a questionar a revelação da soropositividade para o parceiro. 0 profissional podeinvestigar seo parceiro chegou a fazer a testagem e, em caso negativo, pode amadurecer a idéia de que isso seria o ideal, contra-argumentar com o paciente fazendo com que ele se coloque no lugar do outro, explicar os mecanismos detransmissão das DST, a possibilidade de ocorrência de casos assintomáticos e de complicações graves, e assim motivá-lo a trazer seu parceiro para a testagem.

A convocação dos parceiros sexuais é de extrema importância para que eles possam buscar atendimento especializado o mais breve possível. Todos têm o direito de saber sobre sua condição de saúde como também de ter acompanhamento e tratamento pelo serviço. A pessoa soropositiva tem o dever de proteger seus parceiros sexuais, comunicando sua condição sorológica eusando preservativo em todas as relações sexuais.

Não se pode proteger um sujeito e deixar 0 outro desamparado. Então, surge um questionamento: atéque ponto pode-se manter a privacidade e sigilo do portador do vírus da aids e omitir sua soropositividade, colocando em risco outras pessoas?

Não basta que o profissional tenha o domínio técnico. É fundamental queeletenha um cuidar ético; levar em conta a vida e defendêla, con- siderando a necessidade do cliente, mas sem julgá-lo, discriminá-lo ou estigmatizá-lo, sem perder de vista o cuidado ao outro. É preciso articular liberdade e responsabilidade, liberdade no sentido da ação, assumindo a responsabilidade frente a seus atos.

É importante que o profissional não se deixe tomar por sentimentos de penalização, muitas vezes paralisante frente ao cliente e à gama de sofrimentos por que ele passa, pois, no momento em que isso ocorre, o profissional se despotencializa, minimizando sua capacidade ética e desconsiderando o cuidado ao outro. Trabalhar com a convocação de parceiros não é fácil, pois essa abordagem é permeada de dilemas éticos que podem nos barrar, nos paralisar.

Para que a convocação de parceiros seja bem sucedida, Teixeira ${ }^{15}$ concluiu, através do seu estudo em um Serviço Ambulatorial Especializado (SAE), onde os profissionais fazem o aconsel hamento, que a instituição não oferece estrutura física e organizacional para a realização da convocação dos parceiros sexuais HIV/aids.

Surge, assim, a necessidade de planejamento de um serviço ou protocolo que facilite o processo de convocação de parceiros, possibilitando que o profissional tenha um melhor manejo desse pacienteem relação à adesão ao tratamento, principalmente, à comunicação dos parceiros sexuais. Faz-se necessária a criação de um protocolo que permita que o profissional faça a convocação dos parceiros, podendo desta forma dar continuidade a suas condutas e avaliar se esse paciente está voltando ao serviço com seu parceiro sexual.

\section{Consideraçõesfinais}

O cuidado, que a priori é a essência do existir humano ou uma responsabilidade com o outro, não deve ser restrito ao portador do HIV/aids, mas sim expandido para os seus parceiros com quem mantém relações e que estão vulneráveis à contaminação pelo HIV.

É interessante que a equipe profissional do aconselhamento seja mais coesa, colocando em prática conceitos de interdisciplinaridade, multidisciplinaridade, referência, contrarreferência e cuidado ético, utilizando-sesemprededelicadeza, que é um modo sutil e suave de contornar situações difíceis, de fragilidade frente à revelação do resultado do exame anti-HIV e à revelação da soropositividade para os parceiros sexuais.

Defendemosqueo atendimento feito no SAE destinado à entrega de preservativos realizada 
pela equipeinterdisciplinar seja o momento ideal para reforçar o tema da convocação do parceiro sexual. Acreditamos ser esse momento a chance que o profissional de saúde tem de manter um vínculo com o paciente, fazendo questionamentos sobre sua sexualidade, adesão ao tratamento, como também sobre a comunicação da sua soropositividade para a sua parceria sexual. Além de que, nesse atendimento, já se disponibiliza o nome e o número do prontuário do paciente, 0 que torna possível fazer um diagnóstico da sua condição dentro do serviço. Assim, é possível fazer o registro de informações importantes no prontuário, possibilitando uma sistematização da convocação, além de tornar essas informações disponíveis para os outros profissionais, permitindo que estes atuem de modo a ajudar 0 paciente a enfrentar as dificuldades descritas por ele. Dessa forma, é necessária a criação de um protocolo eticamente legal que formalize a convocação do parceiro sexual dando segurança aos profissionais em suas decisões.

D efendemos que o cuidado deve ser resgatado tanto nas relações cotidianas, como no pensar e fazer enfermagem, utilizando-se sempre da delicadeza. No momento atual, em que a humanidade defronta-secom violência, pobreza, maus tratos por parte do outro - seja ele Estado ou pessoa -, agressividade, brutalidade, ira, destrato com o corpo e com as idéias, é necessário, mais do quenunca, por parte de todos, o resgate da delicadeza nas relações pessoais e profissionais. Acreditamos que a atividade do profissional de saúde na convocação de parceiros sexuais em HIV/aids é delicada, pois esse profissional se encontra entre dois polos antagônicos, que são 0 direito do paciente em preservar o sigilo de sua condição sorológica e o direito do parceiro em conhecer as vulnerabilidades do outro. Logo, 0 profissional se encontra em um dilema que necessita ser trabalhado com delicadeza e ética.

\section{Colaboradores}

PM Luz e KCL Miranda participaram igualmente de todas as etapas da elaboração do artigo.

\section{Referências}

1. Silva Júnior AG, Alves CA, M ello Alves M GM. Entre tramas e redes: cuidado e Integralidade. In: Pinheiro R, M attos RA, organizadores. Construção social da demanda. Rio de Janeiro: ABRASCO; 2005. p. 65-112.

2. Boff L. Saber cuidar. Ética do humano - compaixão pela terra. Petrópolis: Vozes; 2000.

3. Barreto JAE, M oreira RVO. A decisão de Saturno: filosofia, teorias de enfermagem e cuidado humano. Fortaleza: Coleção Alagadiço N ovo; 2000.

4. Noddings N. 0 cuidado: uma abordagem feminina à ética e à educação moral. São Leopoldo: Usininos; 2003.

5. Foucault M. 0 uso dos prazeres. 7 a ed. Rio de Janeiro: Graal; 1994

6. Waldow VR. Cuidado humano: o resgate necessário. Porto Alegre: Saga Luzatto; 1999.

7. Taylor FW. Princípios de administração científica. 7ạ ed. São Paulo: Atlas; 1970.

8. Carpenitto LJ. Diagnóstico de Enfermagem: aplicação à prática clínica. 6ạ ed. Porto Alegre: Artes Mé dicas; 1997.

9. Farthing CF, Simone EB, Richard CDS. Atlas colorido de Aids e da doença do HIV. 2ª ed. Porto Alegre: Artes M édicas; 1989.
10. Brasil. Ministério da Saúde. Boletim Epidemiológico AIDS 2000; Ano XIII, número 3. Brasília: Coordenação Nacional de DST e Aids; 2000.

11. Ferreira M PS, Silva CM FP, Gomes MCF, Silva SM B. Testagem sorológica para o HIV e a importância dos Centros de Testagem e Aconselhamento (CTA) - resultados de uma pesquisa no município do Rio de Janeiro. Cien Saude Colet 2001; 6(2):481-490.

12. Brasil. Ministério da Saúde. Diretrizes dos Centros de Testagem e Aconselhamento CTA: M anual. Brasília: Coordenação Nacional de DST e Aids; 1999.

13. M iranda KCL, Barroso M GT. Aconselhamento em HIV/Aids: análise à luz de Paulo Freire. Rev Latino-am Enfermagem 2007; 15(1):100-105.

14. Oliveira LA, Landroni MAS, Kurokawa e Silva NE, Ayres JRCM . Humanização e cuidado: a experiência da equipe de um serviço de DST/Aids no município de São Paulo. Cien Saude Colet 2005; 10(3):689-698.

15. Teixeira JMC. Convocação de parceiros sexuais em serviço ambulatorial especializado em HIV/aids: reflexões e desafios [monografia]. Fortaleza (CE): Universidade Estadual do Ceará; 2006.

Artigo apresentado em 06/08/2007

Aprovado em 29/10//2007

Versão final apresentada em 30/11/2007 